\title{
Use of Rice Husk-Bark Ash in Producing Self-Compacting Concrete
}

\author{
Sumrerng Rukzon ${ }^{1}$ and Prinya Chindaprasirt ${ }^{2}$ \\ ${ }^{1}$ Department of Civil Engineering, Faculty of Engineering, Rajamangala University of Technology Phra Nakhon (RMUTP), \\ Bangkok 10800, Thailand \\ ${ }^{2}$ Sustainable Infrastructure Research and Development Center, Department of Civil Engineering, Faculty of Engineering, \\ Khon Kaen University, Khon Kaen 40002, Thailand
}

Correspondence should be addressed to Sumrerng Rukzon; rerng197@rmutp.ac.th

Received 4 January 2014; Accepted 2 May 2014; Published 14 May 2014

Academic Editor: Harun Tanyildizi

Copyright (C) 2014 S. Rukzon and P. Chindaprasirt. This is an open access article distributed under the Creative Commons Attribution License, which permits unrestricted use, distribution, and reproduction in any medium, provided the original work is properly cited.

\begin{abstract}
This paper presents the use of blend of Portland cement with rice husk-bark ash in producing self-compacting concrete (SCC). CT was partially replaced with ground rice husk-bark ash (GRHBA) at the dosage levels of $0 \%-40 \%$ by weight of binder. Compressive strength, porosity, chloride penetration, and corrosion of SCC were determined. Test results reveal that the resistance to chloride penetration of concrete improves substantially with partial replacement of CT with a blend of GRHBA and the improvement increases with an increase in the replacement level. The corrosion resistances of SCC were better than the CT concrete. In addition, test results indicated that the reduction in porosity was associated with the increase in compressive strength. The porosity is a significant factor as it affects directly the durability of the SCC. This work is suggested that the GHRBA is effective for producing SCC with $30 \%$ of GHRBA replacement level.
\end{abstract}

\section{Introduction}

Self-compacting concrete (SCC) is featured in its fresh state by high workability and rheological stability. SCC has excellent applicability for elements with complicated shapes and congested reinforcement [1]. In concrete materials, most of the previous works studied the effects of pozzolanic materials on physical and mechanical properties of normal concrete. The pozzolanic materials such as fly ash, rice husk ash, palm oil fuel ash, bagasse ash, and rice husk-bark ash are used in the production of concrete instead of using the cement only [2-6].

In Thailand, rice husk-bark ash is a residue obtained from the burning of rice husk-bark as fuel source in the small power generation plants (Thai Power Supply Company Ltd., in Chachoengsao Province). Two portions of rice husk and one portion of eucalyptus bark are the normal composition and it is burnt at $800-900^{\circ} \mathrm{C}$ [7]. The landfills of rice husk-bark ash are still the problem of power generation plants because this waste ash is currently not useful for any works. There are few researches about the rice husk-bark ash characteristics and its mechanical properties relating to the normal concrete work. Therefore, the purpose of this research is to utilize the rice husk-bark ash as pozzolanic material for partly replacing Portland cement in order to produce self-compacting concrete (SCC) as well as reduce negative environmental effects and landfill volume, which is required for eliminating the waste of ash.

\section{Materials and Experiment Details}

2.1. Materials. Portland cement type I (CT) and rice huskbark ash (from Thai Power Supply Company Ltd., in Chachoengsao Province, Thailand) and Superplasticizer (Viscocrete by SIKA; SP) were the materials used for this study. Local crushed limestone was used as coarse aggregate. Graded river sand was used as fine aggregate. Rice husk-bark ash (GRHBA) was ground by a ball mill until $5 \%$ weight retained on a sieve number 325 . The increase in fineness of pozzolanic materials 
TABLE 1: The mechanical properties of cement and pozzolanic materials.

\begin{tabular}{lcc}
\hline Physical properties & CT & GRHBA \\
\hline Median particle size $(\mu \mathrm{m}), d_{50}$ & 25.0 & 20 \\
Retained on a sieve number $325(\%)$ & N/A & 5 \\
Specific gravity & 3.14 & 2.23 \\
Blaine fineness $\left(\mathrm{cm}^{2} / \mathrm{gm}\right)$ & 3.600 & 11.000 \\
\hline
\end{tabular}

TABLE 2: Chemical components of CT and pozzolanic materials [4].

\begin{tabular}{lcc}
\hline Oxides (\%) & CT & GRHBA \\
\hline $\mathrm{CaO}(\%)$ & 54.9 & 5.5 \\
$\mathrm{SiO}_{2}(\%)$ & 25.0 & 76.0 \\
$\mathrm{Al}_{2} \mathrm{O}_{3}(\%)$ & 5.5 & 1.5 \\
$\mathrm{Fe}_{2} \mathrm{O}_{3}(\%)$ & 5.5 & 1.5 \\
$\mathrm{MgO}(\%)$ & 3.0 & 0 \\
$\mathrm{~K}_{2} \mathrm{O}(\%)$ & 0.5 & 3.9 \\
$\mathrm{SO}_{3}(\%)$ & 4.5 & 0.9 \\
$\left.\mathrm{LOI}^{2} \%\right)$ & 0.9 & 8.2 \\
$\mathrm{SiO}_{2}+\mathrm{Al}_{2} \mathrm{O}_{3}+\mathrm{Fe}_{2} \mathrm{O}_{3}(\%)$ & - & 79.0 \\
\hline
\end{tabular}

increased the surface area and the reaction [2-6]. Physical properties of type I Portland cement (CT) and ground rice husk-bark ash (GRHBA) are shown in Table 1.

The chemical composition of CT and GRHBA is shown in Table 2. GRHBA is composed of $76.0 \% \mathrm{SiO}_{2}$ with $8.2 \%$ LOI. The sum of $\mathrm{SiO}_{2}+\mathrm{Al}_{2} \mathrm{O}_{3}+\mathrm{Fe}_{2} \mathrm{O}_{3}$ was $79.0 \%$. GRHBA could be classified as class $\mathrm{N}$ pozzolanic material $[4,8]$.

2.2. Mix Proportions of SCC and Curing. Portland cement type I (CT) was partially replaced with GRHBA at the dosages of $0 \%, 20 \%, 30 \%$, and $40 \%$. CT was partially replaced with pozzolans in order to produce self-compacting concrete (SCC) with compressive strength at 28 days higher than $20.0 \mathrm{MPa}$ (design at the age of 28 days). The content of cementitious materials (B) was maintained at $650 \mathrm{~kg} / \mathrm{m}^{3}$. All concrete mixtures had constant water to binder ratio (W/B) of 0.46. A slump flow ranking from 650 to $800 \mathrm{~mm}$ is considered as the slump flow required for self-compacting concrete [9]. Therefore, a Superplasticizer or SP (Viscocrete by SIKA) was used for maintaining high workability with slump flow of 650-800 mm.

The cast specimens were covered with polyurethane sheet and damped cloth and placed in $23 \pm 2^{\circ} \mathrm{C}$ chamber for one day. After that, they were demoulded and were cured in water at $23 \pm 2^{\circ} \mathrm{C}$ until the test age. The self-compacting concrete (SCC) mix proportions are given in Table 3.

2.3. Compressive Strength Test. The $100 \mathrm{~mm}$ diameter and $200 \mathrm{~mm}$ height cylindrical specimens were used for compressive strength testing. The compressive strength test was carried out as per ASTM C39 [10]. They were tested at the ages of 7, 28, and 90 days. The reported results are the average of three samples.

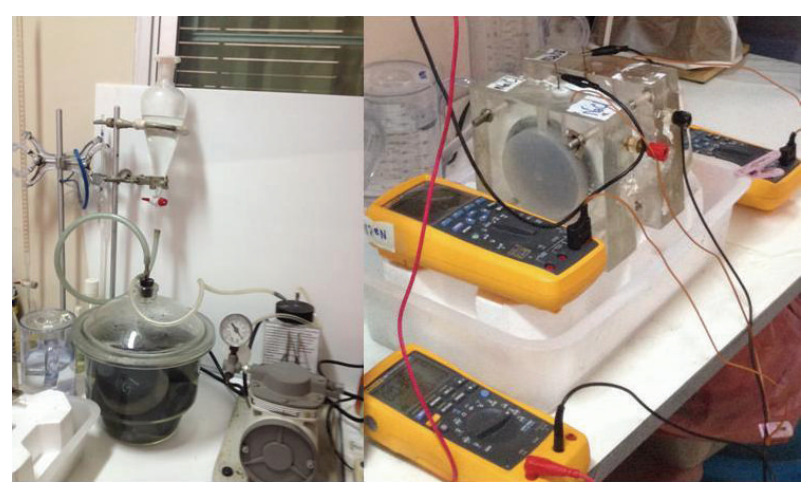

Figure 1: The RCPT test setup with ASTM C1202 [11].

2.4. Porosity Test. For porosity test, SCC were cut into $50 \mathrm{~mm}$ thick slices and the $50 \mathrm{~mm}$ ends were discarded. They were dried at $100 \pm 5^{\circ} \mathrm{C}$ until the weight was constant. They were then placed in desiccators under vacuum for 3 hours. The setup was finally filled with deaired and distilled water in order to measure the effective porosity of concrete at the ages of 7,28 , and 90 days. The porosity was calculated by using $[3,4]$

$$
P(\%)=\left[\frac{\left(W_{a}-W_{d}\right)}{\left(W_{a}-W_{w}\right)}\right] \times 100,
$$

where $P(\%)$ is vacuum saturated porosity, $W_{a}$ is the weight of specimen in the air at saturated condition $(\mathrm{g}), W_{d}$ is the dry weight of the specimen after 24 hours in oven at $100 \pm 5^{\circ} \mathrm{C}(\mathrm{g})$, and $W_{w}$ is the weight of the specimen in water $(\mathrm{g})$.

2.5. Rapid Test on Resistance to Chloride Penetration. The $100 \mathrm{~mm} \times 200 \mathrm{~mm}$ cylinders were prepared in accordance with ASTM C39 [10]. This study considers the amount of the chloride penetration, which is measured by Coulomb (charge passed). After the cylinders had been cured in water for 6, 27, and 89 days (arranged for the test at the ages of 7 , 28 , and 90 days), they were cut into $50 \mathrm{~mm}$ thick slices and the $50 \mathrm{~mm}$ ends were discarded. The $50 \mathrm{~mm}$ slices were then coated with epoxy around the cylindrical surface. They were tested for rapid chloride penetration test (RCPT) the next day in accordance with the method described in ASTM C1202 [11]. The reported results are the average of four samples. The RCPT test setup is shown in Figure 1.

2.6. Accelerated Corrosion Test. This test was successfully used on the previous research work on the corrosion of mortar and concrete containing pozzolans $[2,3,11,12]$. The $100 \mathrm{~mm} \times 100 \mathrm{~mm}$ SCC cubes with embedded steel of $12 \mathrm{~mm}$ diameter and $200 \mathrm{~mm}$ length were used for this test. For anode, the steel was secured such that it protruded from the top surface of the cube by $44 \mathrm{~mm}$, thus providing sufficient concrete covers of $44 \mathrm{~mm}$ at the bottom and the sides of the prism as shown in Figure 2. At the ages of 7, 28, and 90 days, the concretes were subjected to the accelerated corrosion test with impressed voltage using a $5 \% \mathrm{NaCl}$ solution and a constant voltage of 12 -volt dc (for cathode). The condition of 
TABLE 3: Self-compacting concrete mixture proportions.

\begin{tabular}{|c|c|c|c|c|c|c|c|c|}
\hline \multirow{2}{*}{ Mix } & \multirow{2}{*}{${ }^{*} \mathrm{~W} / \mathrm{B}$ or ${ }^{*} \mathrm{~W} / \mathrm{C}$} & \multicolumn{5}{|c|}{ Mix proportions $\left(\mathrm{kg} / \mathrm{m}^{3}\right)$} & \multirow{2}{*}{ SP } & \multirow{2}{*}{ Flow $(\mathrm{mm})$} \\
\hline & & Cement & GRHBA & Fine aggregate & Coarse aggregate & Water & & \\
\hline $\mathrm{CT}$ & 0.46 & 650 & 0 & 780 & 975 & 299 & 3 & 720 \\
\hline 20 GRHBA & 0.46 & 520 & 130 & 780 & 975 & 299 & 5 & 740 \\
\hline 30 GRHBA & 0.46 & 455 & 195 & 780 & 975 & 299 & 6 & 750 \\
\hline 40 GRHBA & 0.46 & 390 & 260 & 780 & 975 & 299 & 7 & 745 \\
\hline
\end{tabular}

Note. ${ }^{*} \mathrm{~W} / \mathrm{B}$ : water cement to binder ratio (B: cementitious materials), C, CT: cement, and SP: Superplasticizer (Viscocrete by SIKA).

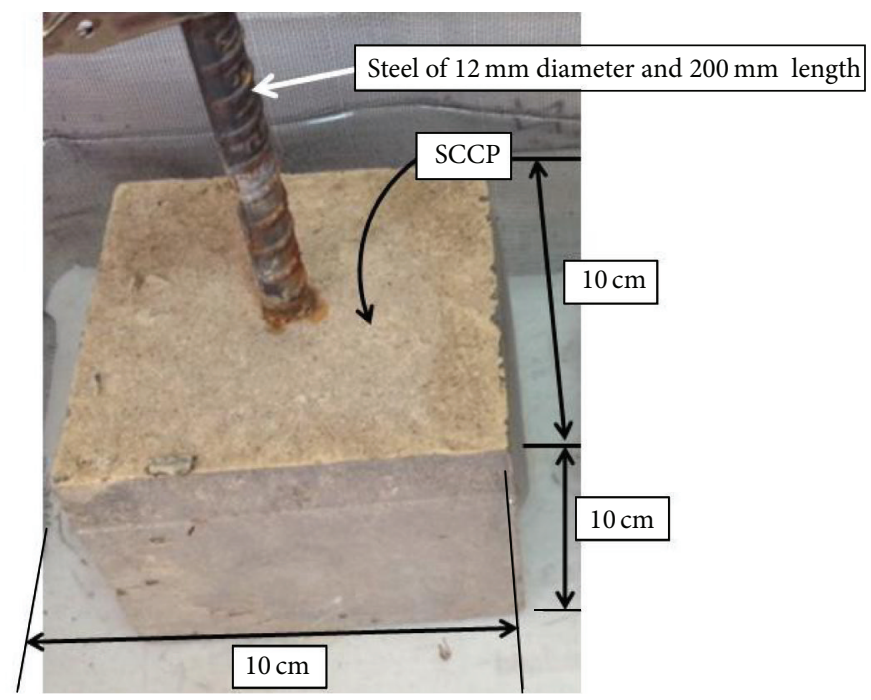

FIGURE 2: Concrete prism for accelerated corrosion test.

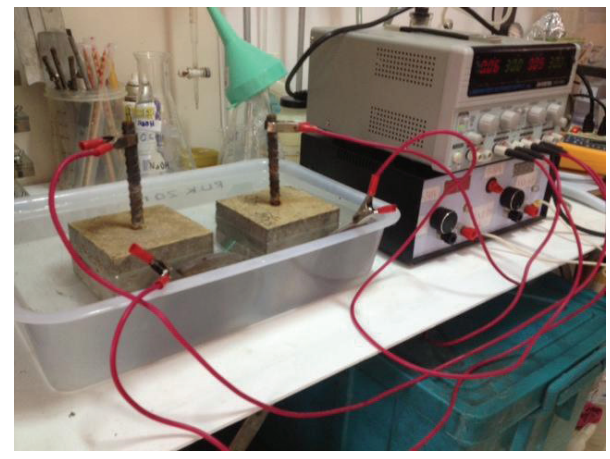

FIGURE 3: The accelerated corrosion test setup.

SCC was monitored visually at the interval of 4 hours and the time of initiation of first crack was recorded. The accelerated corrosion test setup is shown in Figure 3.

\section{Results and Discussions}

3.1. SP Requirement and Compressive Strength of SCC. The results of the required SP of SCC are given in Table 3. The incorporation of GRHBA increased the amount of SP required, compared to the control concrete (CT). The increase in SP was associated with the increase in the amount of GRHBA. This is due to the specific surfaces and the cellular structure of the particles. Furthermore, LOI of GRHBA was high at $8.2 \%$. So, the amount of SP requirement was increased. This result is similar to the last researches [3]. In addition, test results indicate that the slump flow was between 720 and $750 \mathrm{~mm}$, which is considered as the slump flow required for self-compacting concrete [9].

The results of compressive strengths and the normalized compressive strengths are presented in Figures 4 and 5, respectively. The strengths of SCC developed continuously. The normalized compressive strengths at 7,28, and 90 days of 20 GRHBA concretes were in the range of $95 \%-105 \%$ of the CT concrete and those of 30 GRHBA and 40 GRHBA concretes were in the range of $72 \%-98 \%$ of the CT concretes. The strength of the GRHBA concrete was lower than that of CT concretes because the GRHBA mixes required more SP and resulted in the porosity of GRHBA and the cellular structure of the particles [3]. The compressive strength varies from 25.5 to $27 \mathrm{MPa}$, which is higher than $20.0 \mathrm{MPa}$ (design at the age of 28 days). Therefore, referring to the range of this compressive strength of these SCC, it is suggested that the GHRBA is effective for producing self-compacting concrete with $20 \%-30 \%$ of GHRBA replacement (Figure 6).

3.2. Porosity of SCC. The results of porosity of SCC concrete are given in Figure 7 . The results indicate that the porosities of SCC reduced with the curing time due to the additional hydration and/or pozzolanic reaction [3]. The products of 


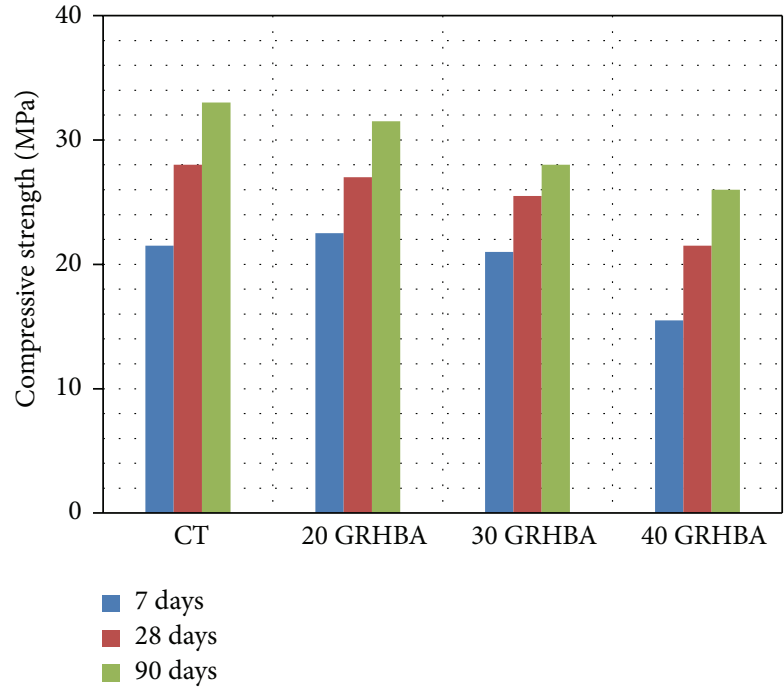

FIGURE 4: Compressive strength of SCC.

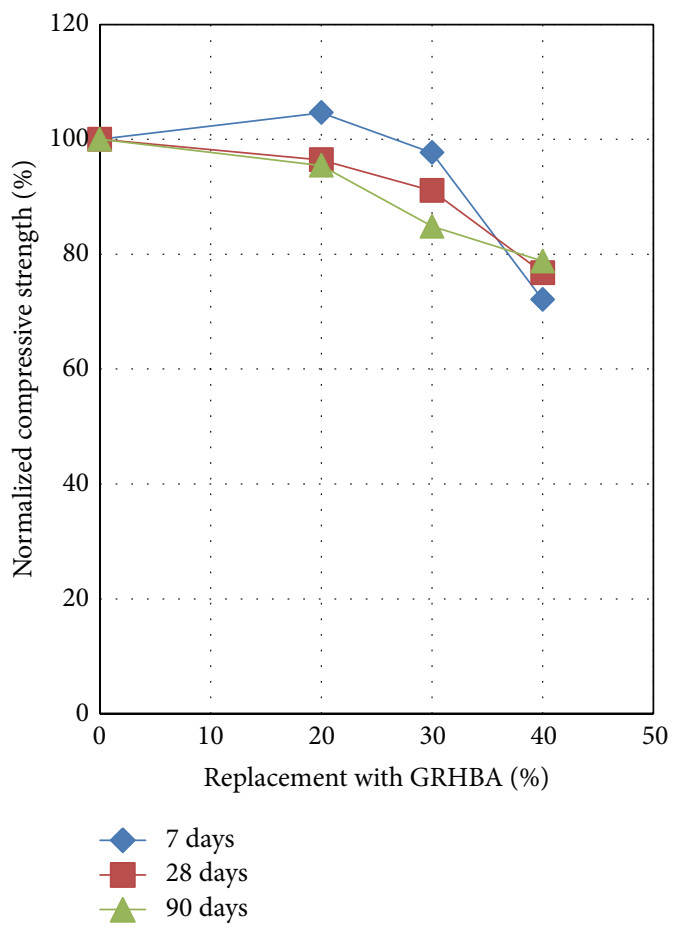

FIGURE 5: Normalized compressive strength of SCC.

hydration and/or pozzolanic reaction between $\mathrm{Ca}(\mathrm{OH})_{2}$ and $\mathrm{SiO}_{2}$ filled the voids and increased the density of concrete [3]. The porosity of the SCC with $20 \%$ of GHRBA is less than that of the SCC with $40 \%$ of GHRBA. GHRBA replacement increased the porosity of SCC. In addition, the results as shown in Figure 8 also indicated that the reduction in porosity was associated with the increase in compressive strength. Therefore, the porosity is a significant factor as it affects directly the compressive strength of the self-compacting concrete $[3,4]$.

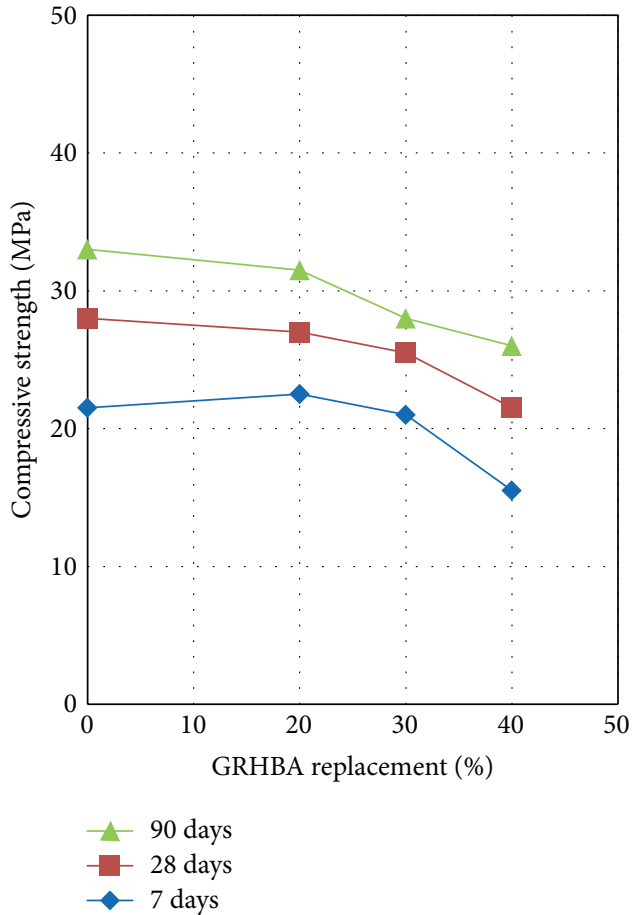

FIgURE 6: Relationship between compressive strength and \% of GRHBA replacement.

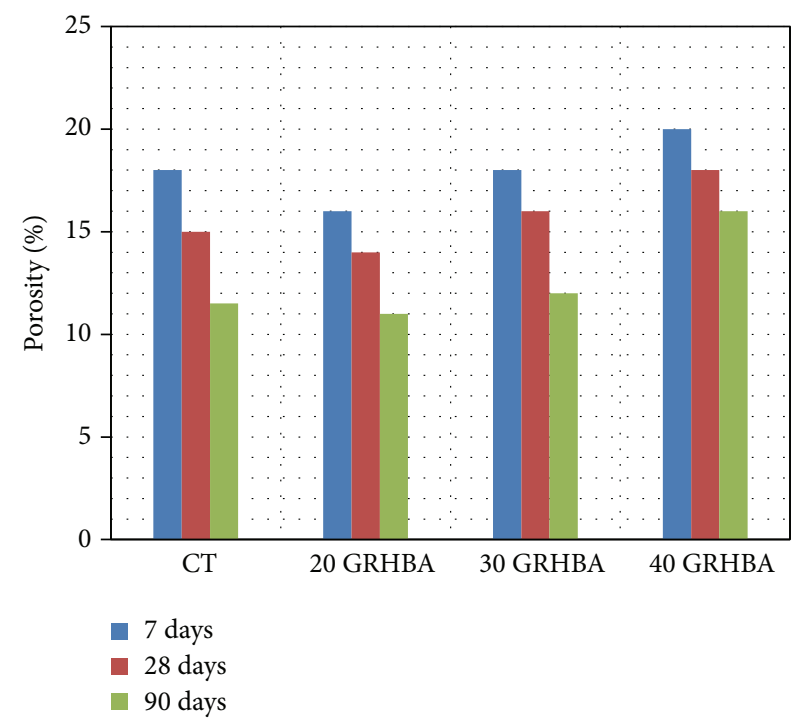

Figure 7: Porosity of SCC.

3.3. Chloride Penetration of Concrete. The results of the chloride resistance test of the self-compacting concrete (SCC) at 7, 28, and 90 days are presented in Figure 9. This chloride resistance study is based on the ASTM standard [11]. The results indicate that replacements of CT with GHRBA reduced the charge passed (Coulomb) indicating the increase in the resistance to chloride penetration. The fine particles of GHRBA (after being ground) could fill the void and also 


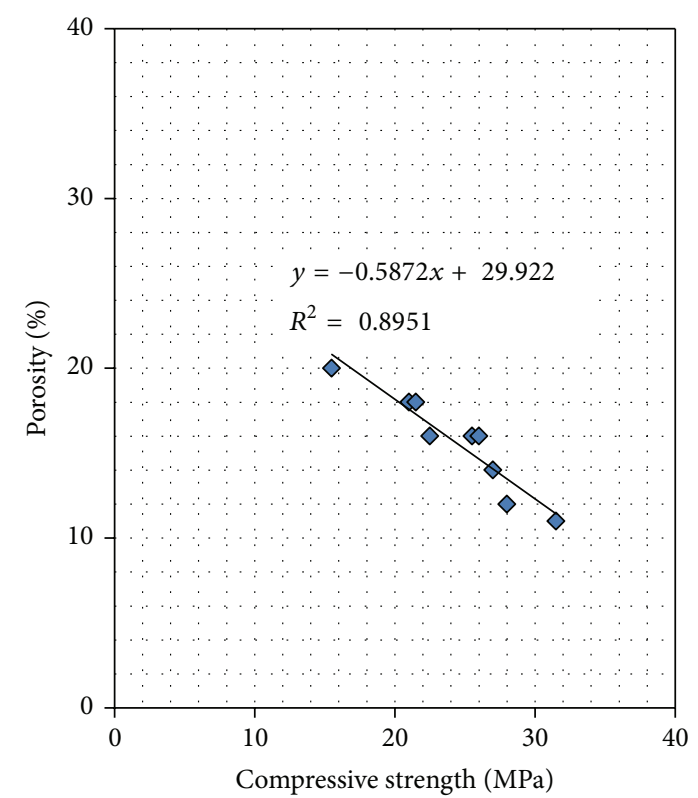

FIGURE 8: Relationship between compressive strength and porosity of SCC.

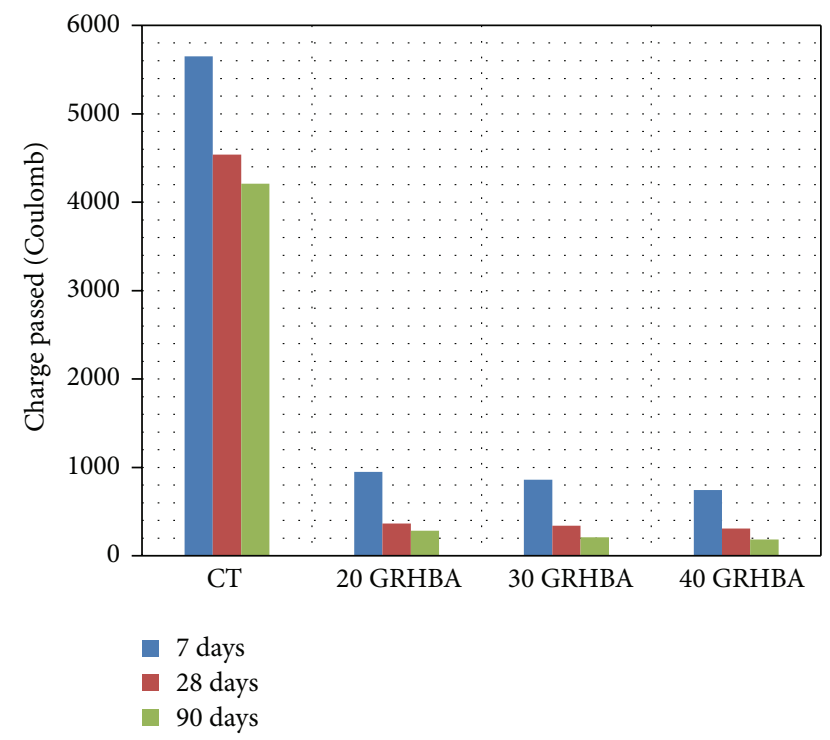

FIGURE 9: Chloride penetration of SCC with RCPT [11].

caused the nucleation sites for the acceleration of the hydration reaction in the cement paste $[3,4,13]$. The resistance to chloride penetration increased with age for all SCC mixes due to the hydration and pozzolanic reaction $[3,4]$. The reaction between $\mathrm{SiO}_{2}$ and $\mathrm{Ca}(\mathrm{OH})_{2}$ produces calcium silicate hydrate $(\mathrm{CSH})$, which increases the density of concrete and contributed to the strength of self-compacting concrete $[3,4,14-$ 16]. The result of this work is useful in order to convince the construction industry for the use of rice husk-bark ash (GHRBA) in producing self-compacting concrete with waste materials.

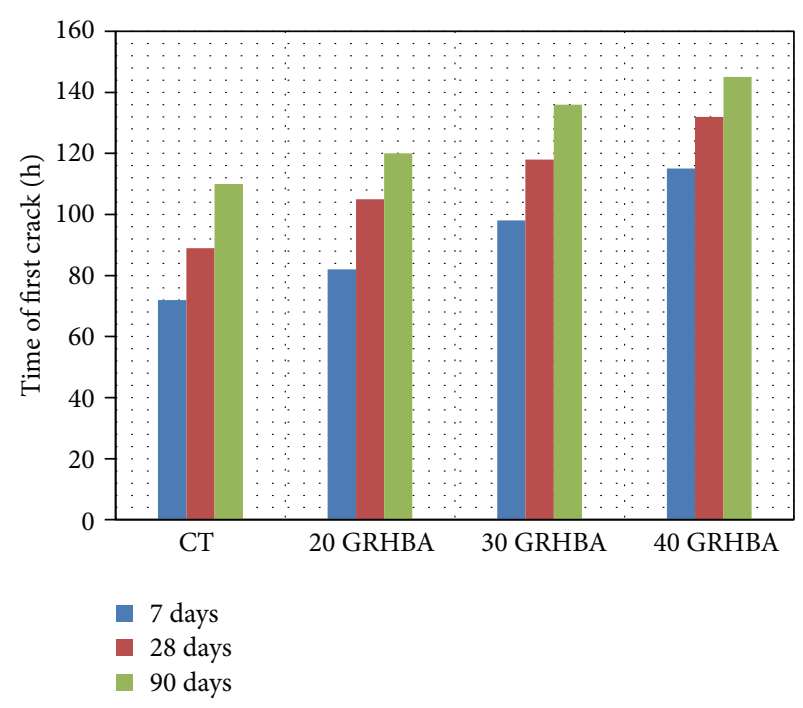

FIgure 10: Time of first crack (h) of SCC.

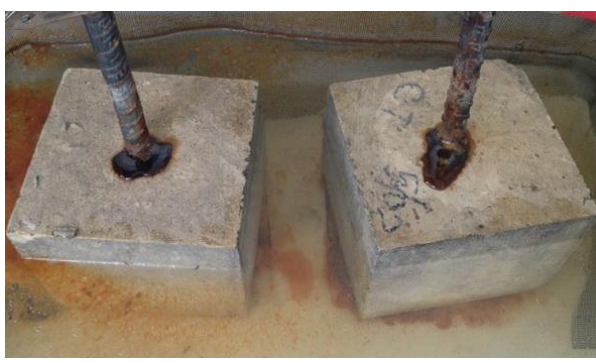

FIGURE 11: Sample of time of first crack.

3.4. Corrosion of SCC. The test result is presented in Figure 10. The replacements of CT with GHRBA increased the times to first crack (hours) indicating the increase in the resistance to corrosion. The times to first crack increased with the increase in the GHRBA content. At the age of 7 days, the time of first crack of self-compacting concrete control (CT) was 72 hours, whereas the time of first crack of selfcompacting concretes containing GHRBA was longer at 82 to 115 hours. At the age of 28 days, the time of first crack of self-compacting concrete control (CT) was 89 hours, whereas the time of first crack of self-compacting concretes containing GHRBA was longer at 105 to 132 hours.

At the age of 90 days, the time of first crack of selfcompacting concrete control (CT) was 110 hours, whereas the time of first crack of self-compacting concretes containing GHRBA was longer at 120 to 145 hours. The time of first crack of SCC increased continuously. This confirms the results of the time of first crack that incorporation of GHRBA improves the resistance to corrosion of self-compacting concretes. The pozzolanic materials increased the reaction products and reduced the volume of the cavities in the paste $[3,4]$. The sample of crack result is shown in Figure 11. 


\section{Conclusions}

From the tests, it can be concluded that GHRBA containing fine irregular-shaped particles increases the amount of SP required. The use of the blend of pozzolans of fine GHRBA also effectively improves the self-compacting concretes (SCC) in terms of corrosion and resistance to chloride penetration. The results indicate that the incorporation of $30 \%$ of GRHBA decreases the corrosion, chloride penetration of selfcompacting concrete. This is due to the fact that the fine particles of GHRBA could fill the void and also caused the nucleation sites for the acceleration of the hydration reaction in the cement paste.

\section{Conflict of Interests}

The authors declare that there is no conflict of interests regarding the publication of this paper.

\section{Acknowledgments}

This work was supported by the Thailand Research Fund (TRF) under the TRF Research Grant for New Scholar no. MRG5580120; Office of the Higher Education Commission (OHEC); Rajamangala University of Technology Phra Nakhon (RMUTP).

\section{References}

[1] L. Ferrara, Y.-D. Park, and S. P. Shah, "A method for mixdesign of fiber-reinforced self-compacting concrete," Cement and Concrete Research, vol. 37, no. 6, pp. 957-971, 2007.

[2] P. Chindaprasirt, C. Chotetanorm, and S. Rukzon, "Use of palm oil fuel ash to improve chloride and corrosion resistance of high-strength and high-workability concrete," Journal of Materials in Civil Engineering, vol. 23, no. 4, pp. 499-503, 2011.

[3] S. Rukzon and P. Chindaprasirt, "Utilization of bagasse ash in high-strength concrete," Materials and Design, vol. 34, pp. 4550, 2012.

[4] S. Rukzon and P. Chindaprasirt, "Strength, porosity and chloride resistance of mortar using combination of two kinds of the pozzolanic materials," International Journal Mineral Metallurgy Materials, vol. 20, no. 8, pp. 808-814, 2013.

[5] S. Rukzon and P. Chindaprasirt, "Chloride penetration and corrosion resistance of ground fly ash blended cement mortar," International Journal of Materials Research, vol. 102, no. 3, pp. 335-339, 2011.

[6] S. Rukzon and P. Chindaprasirt, "Strength and carbonation model of rice husk ash cement mortar with different fineness," Journal of Materials in Civil Engineering, vol. 22, no. 3, pp. 253259, 2010.

[7] V. Sata, C. Jaturapitakkul, and K. Kiattikomol, "Influence of pozzolan from various by-product materials on mechanical properties of high-strength concrete," Construction and Building Materials, vol. 21, no. 7, pp. 1589-1598, 2007.

[8] ASTM C618, "Standard Test Method for Compressive Strength of Cylindrical Concrete Specimens," Annual Book of ASTM Standard, 04.02: 323-325, 2005.

[9] A. Navaneethakrishnan and V. M. Shantih, "Experimental study of self compacting concrete (SCC) using silica fume,"
International Journal of Emerging Trends in Engineering and Development, vol. 4, no. 2, pp. 475-482, 2012.

[10] ASTM C39, "Standard test method for compressive strength of cylindrical concrete specimens," Annual Book of ASTM Standard, 04.01: 21-27, 2005.

[11] ASTM C1202, "Standard Test Method for electrical Indication of Concrete's Ability to Resist Chloride Ion Penetration," Annual Book of ASTM Standard, 04.01: 651-656, 2005.

[12] V. Saraswathy and H.-W. Song, "Corrosion performance of rice husk ash blended concrete," Construction and Building Materials, vol. 21, no. 8, pp. 1779-1784, 2007.

[13] P. K. Mehta, "Studies on the mechanisms by which condensed silica fume improves the properties of concrete: durability aspects," in Proceedings of the International Workshop on Condensed Silica Fume in Concrete, p. 17, Ottawa, Canada, 1987.

[14] A. M. Neville, Properties of Concrete, Longman, Selangor, Malaysia, 4th edition, 1995.

[15] X. He, Y. Chen, B. Ma, Y. Li, H. Zhang, and W. Zhang, "Studies on small ionic diffusivity concrete," in Proceedings of the International Workshop on Sustainable Development Concrete Technology, pp. 319-319, 2001.

[16] F. Leng, N. Feng, and X. Lu, "Experimental study on the properties of resistance to diffusion of chloride ions of fly ash and blast furnace slag concrete," Cement and Concrete Research, vol. 30, no. 6, pp. 989-992, 2000. 

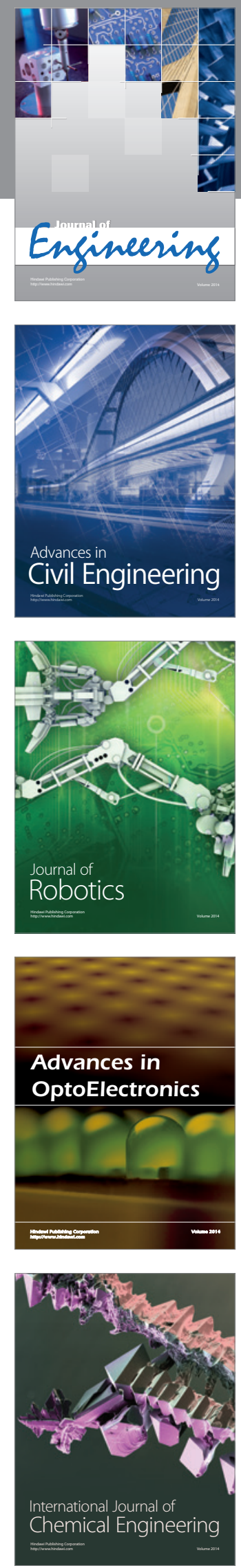

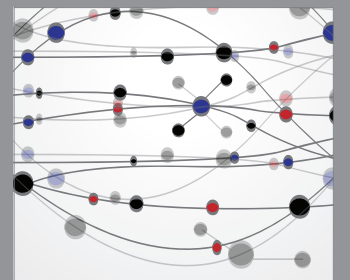

The Scientific World Journal
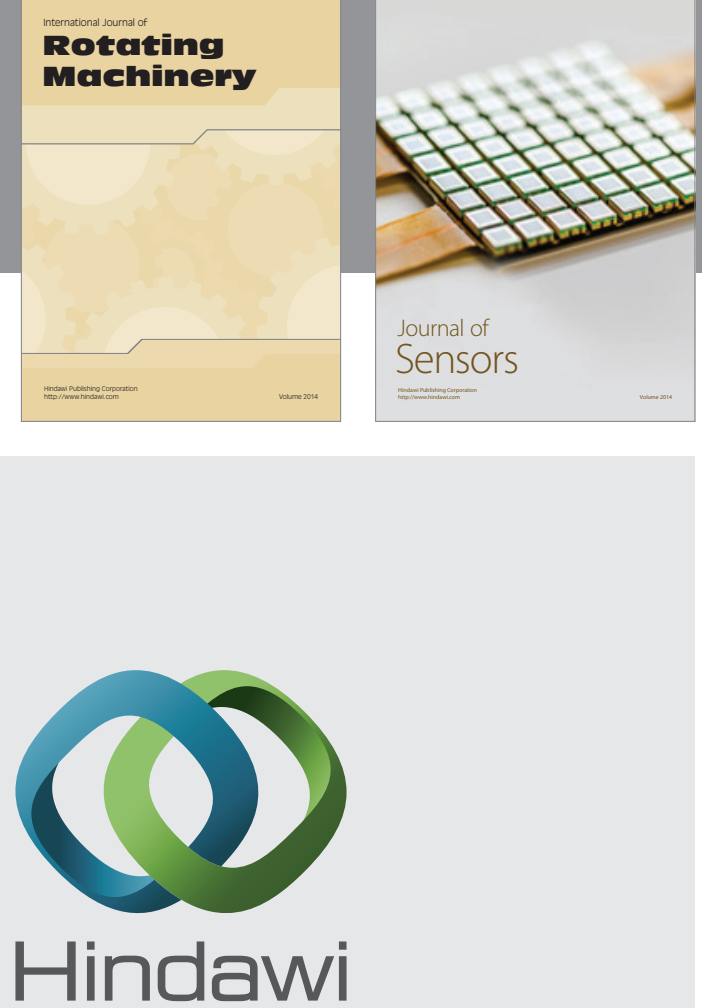

Submit your manuscripts at http://www.hindawi.com
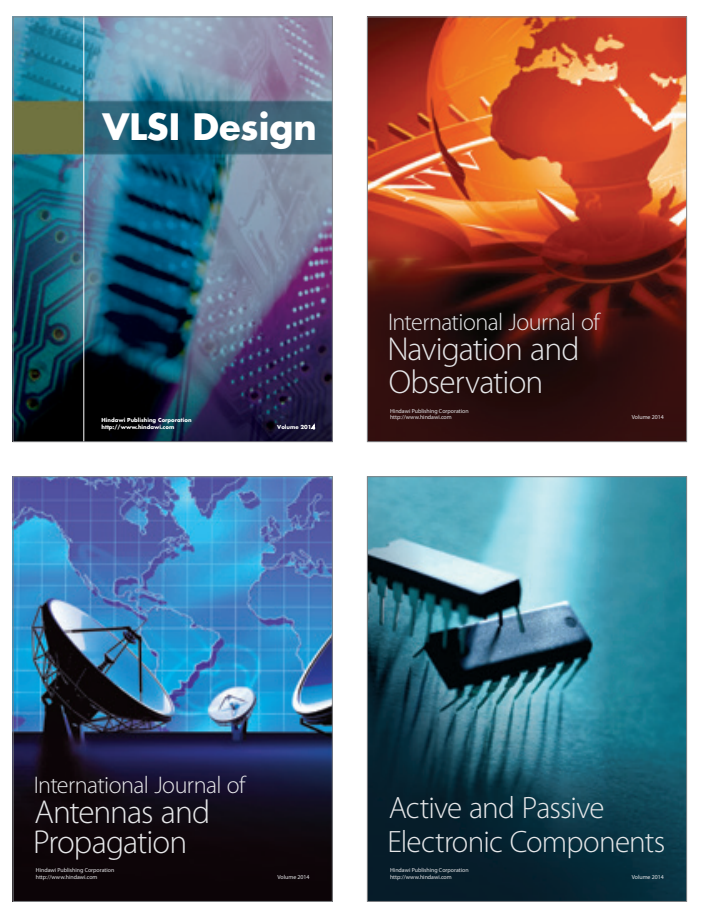
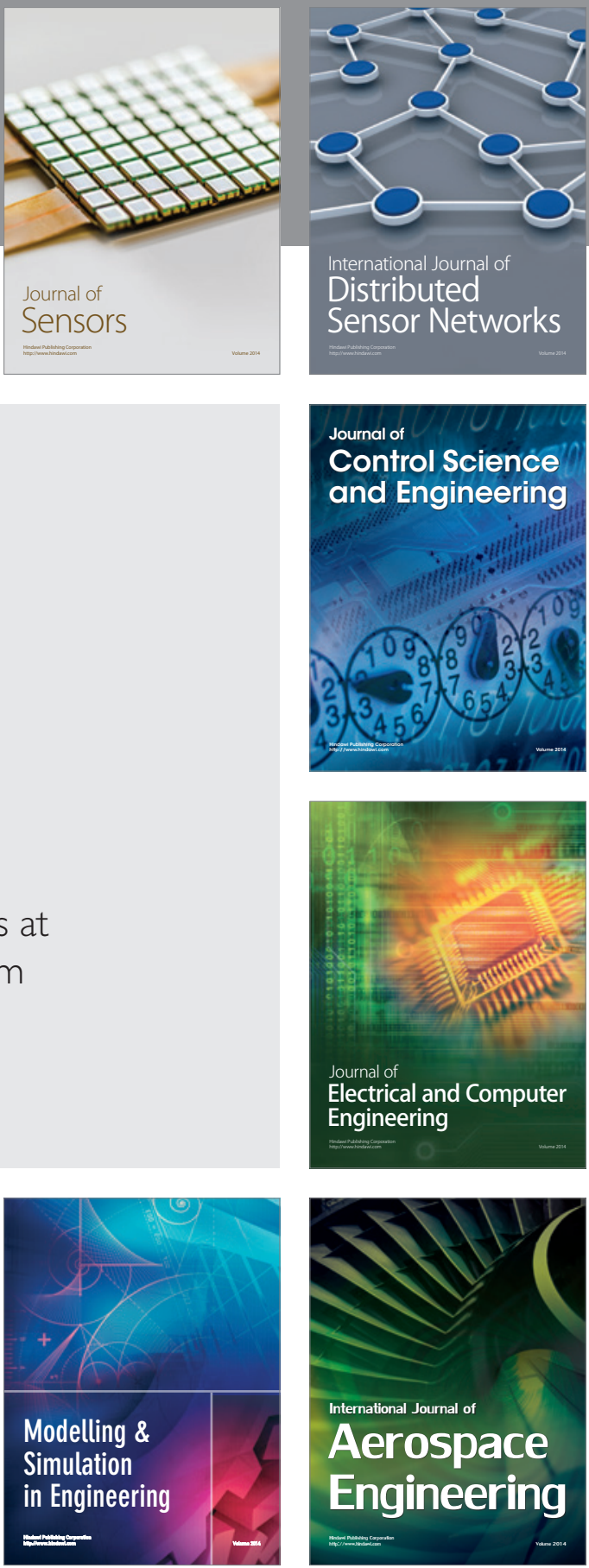

Journal of

Control Science

and Engineering
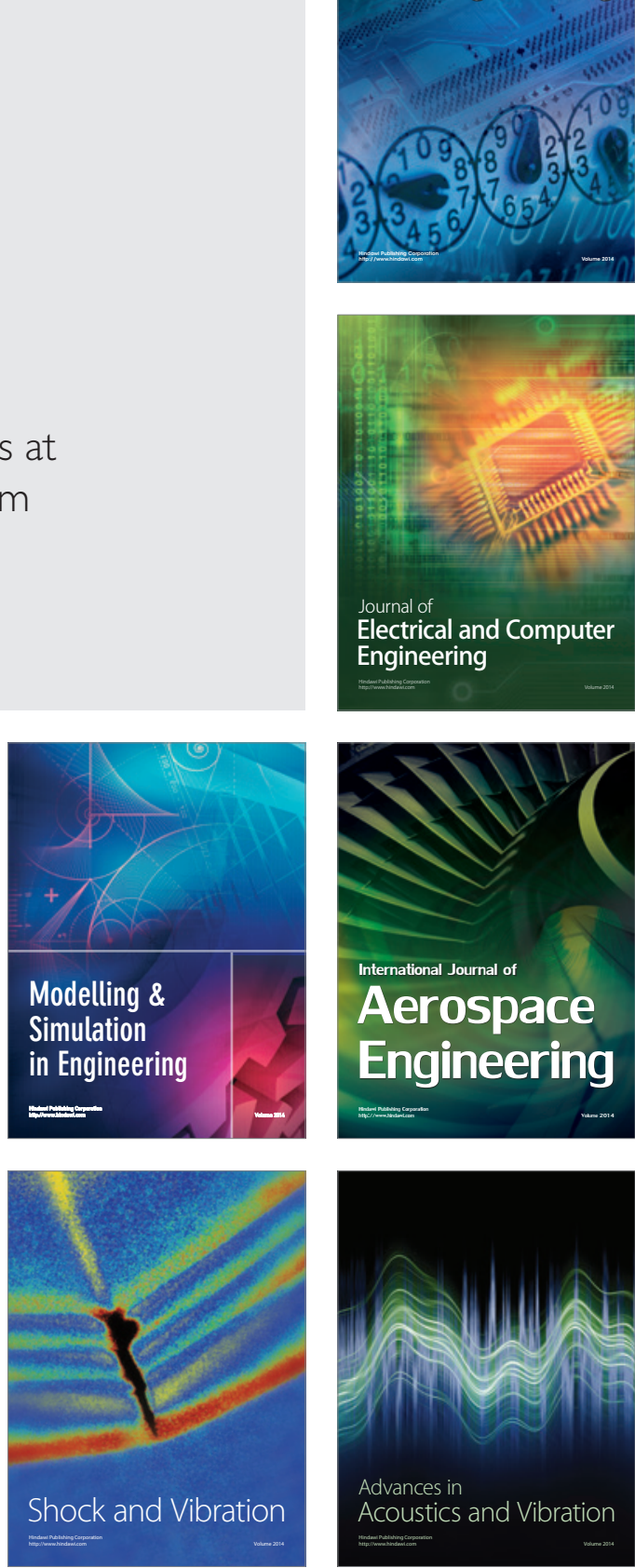